\title{
Analysis of the impact of road construction dust on glacier environment
}

\author{
JingZhao $^{1}$, ShegangShao ${ }^{1}$, DongNi ${ }^{1}$, XiaodongShang ${ }^{1}$, XiaofengLiu ${ }^{2,3}$, QuanZhang ${ }^{4}$ and XiaojuanYu $^{5}$ \\ ${ }^{1}$ Research Institute of Highway Ministry of Transport, Bei jing, 100088, China \\ ${ }^{2}$ China Aviation Planning And Design Institute (GROUP)CO., LTD, Bei jing, China \\ ${ }^{3}$ University of science and technology Beijing, Bei jing, China \\ ${ }^{4}$ Beijing Municipal Engineering Consulting Corporation, Bei jing, China \\ ${ }^{5}$ Beijing Z.D.H.K Environmental Science \&Technology Co.,Ltd
}

\begin{abstract}
Construction dust falls to the snow cover and the surface of the glacier to form a fouling layer to absorb more solar radiation and reduce the intensity of surface albedo, thereby accelerating the melting of the glacier, which is the main factor affecting the glacial environment in the Highway construction. This article adopts the combination method of wind tunnel experiment and numerical simulation was used to calculate the impact range of construction dust. The results show that with increasing of particle size, the diffusion range of dust decreased while the settlement speed increased. High dust concentration area ( $>4 \mathrm{mg}$ $/ \mathrm{m}^{3}$ ) is generally distributed within $1000 \mathrm{~m}$ around the construction site. The specific extension direction is directly related to the local terrain and wind direction, and the height direction is generally not more than $300 \mathrm{~m}$. According to the above simulation results, for preventing and reducing the impact of highway construction on the glacial environment, the requirements of route selection and construction dust control measures was put forward, which played an important role and significance in guiding the highway design and construction and reducing the impact of highway construction on the glacial environment.
\end{abstract}

\section{Introduction}

According to the research of many domestic scholars on glacier melting, the main reasons for the accelerated glacier melting are global warming and absorbing more solar radiation and reducing the intensity of Surface Albedo, which are caused by the polluted layer comprised of the settled trace elements and fly ash particles in the regional atmosphere forms on the snow and glacier surface.

For investigating the road construction dust influence on glacier environment, wind tunnel experiments and numerical simulation are used to simulate the impact range of construction dust, and then evaluate the impact of road construction dust on the glacier environment.

\section{Experimental methods}

\subsection{Wind tunnel experiments}

The experiment was carried out in the multi-functional environmental wind tunnel in Key Laboratory of Research Institute of Highway Ministry of Transport. The total length of the wind tunnel is $38 \mathrm{~m}$, the working section is $12 \mathrm{~m}$ long, $1.5 \mathrm{~m}$ wide and $1.0 \mathrm{~m}$ high. It can simulate the flow of the near-earth wind field in the range of $3-40 \mathrm{~m} / \mathrm{s}$ and carry out relevant simulation experiments.

The arrangement of the environmental wind tunnel is presenting in Figure 1. At the front of the test section, a pitot tube is placed at the axis of the wind tunnel to monitor the wind speed. And a $10 \mathrm{~cm}$ thick loess layer is laid on the surface to simulate the condition of the construction site. For measuring the dust concentration released by wind, a Grimm probe is arranged at the exit which is $14 \mathrm{~cm}$ above the surface at to measure the dust concentration near the formation after the dust release. 


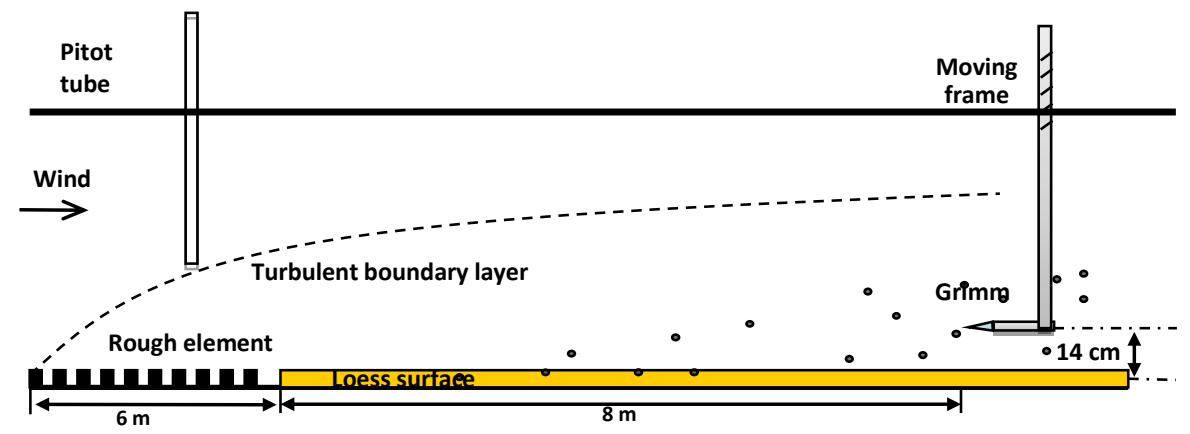

Figure 1. layout of wind tunnel experiment.

According to the annual average wind speed of the study area, the experimental wind speed sets to $12 \mathrm{~m} / \mathrm{s}$, and the dust concentration near the formation when the dust releases under this condition is measured. Each group was measured for $10 \mathrm{~min}$ and repeated three times.
The results are shown in Figure 2. It can see from figure 2 that the dust concentration near the formation is maintained at about $100 \mathrm{mg} / \mathrm{m}^{3}$ when the dust release occurs.

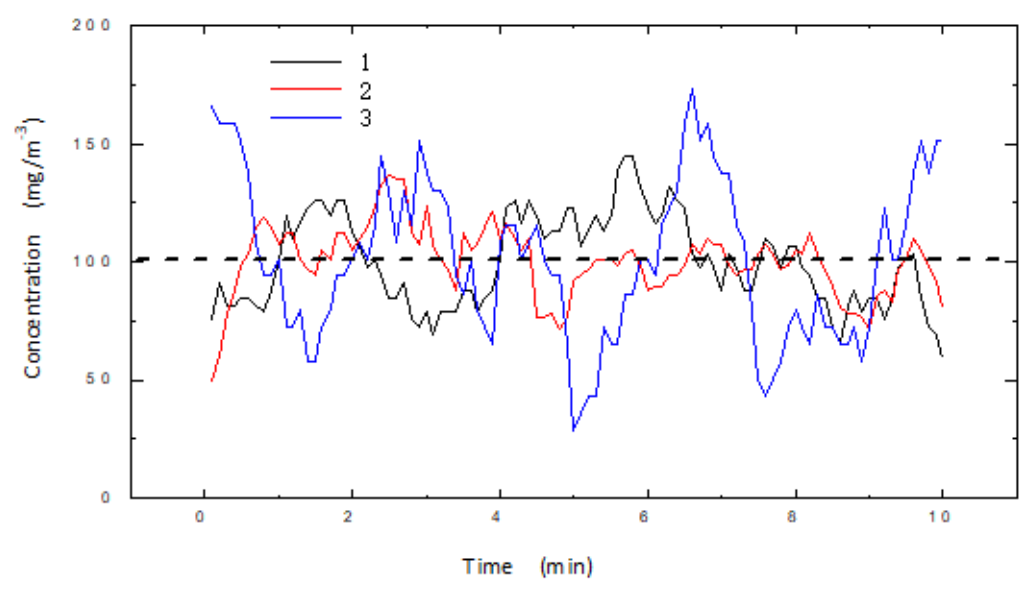

Figure 2. Variation of dust concentration with time.

\subsection{Numerical simulations}

The simulation area is $5000 \mathrm{~m} \times 3000 \mathrm{~m} \times 3000 \mathrm{~m}$, the horizontal grid is $20 \mathrm{~m}$, and the vertical grid is stretched and the minimum grid is $1 \mathrm{~m}$. Terrain data calls highprecision DEM database with a resolution of $30 \mathrm{~m}$, and the generated calculation model is shown in Figure 3.

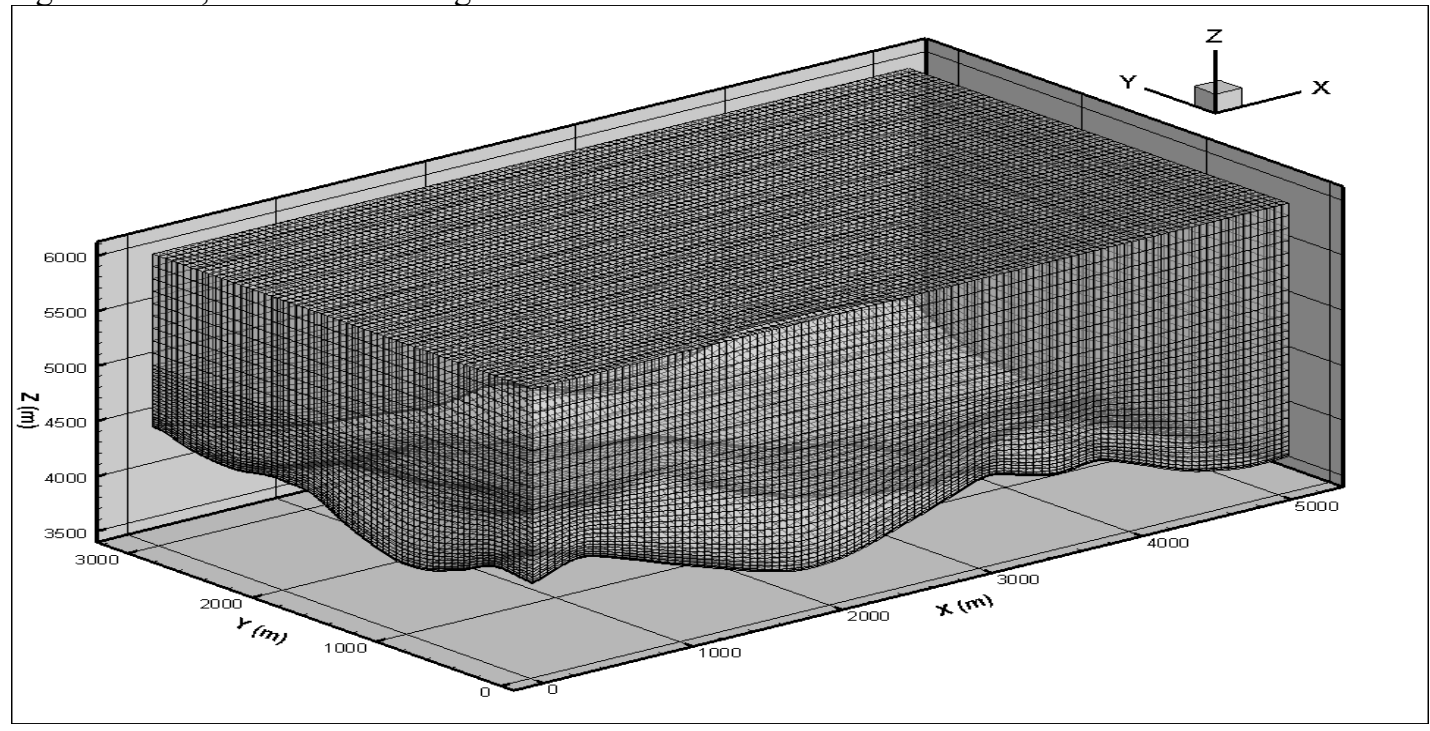

Figure 3. Schematic diagram of calculation model 
The incompressible flow field and dust diffusion of complex three-dimensional terrain are calculated with the advanced regional prediction (ARPS) open code.

After filtering, the governing equation of the flow field is obtained from three-dimensional incompressible and continuous viscosity turbulence governing equation called the N-S equation.

$\frac{\partial \bar{u}_{i}}{\partial x_{i}}=0$

$$
\frac{\partial \bar{u}_{i}}{\partial t}+\bar{u}_{j} \frac{\partial \bar{u}_{i}}{\partial x_{j}}=-\frac{1}{\rho_{f}} \frac{\partial p}{\partial x_{i}}+\frac{\partial}{\partial x_{j}}\left[\nu\left(\frac{\partial \bar{u}_{i}}{\partial x_{j}}+\frac{\partial \bar{u}_{j}}{\partial x_{i}}\right)-\tau_{i j}^{r}\right]+\bar{B}_{i}+\bar{f}_{i}
$$

Where $u_{i}$ is the fluid velocity, $p$ is the total pressure, $v$ is kinematic viscosity of fluid, $\rho_{f}$ is fluid density, $B_{i}$ is gravity and coriolis force, and $i=1,2,3$.

$f_{i}$ is additional volume forces due to the presence of particles, given by equation as follows:

$$
\bar{f}_{i}=-\frac{1}{\rho_{f} V_{\text {grid }}} \sum_{p=1}^{N_{p}} m_{p} \frac{u_{i}\left[x_{p}(t), t\right]-V_{p i}(t)}{\tau_{p}} f\left(\operatorname{Re}_{p}\right)
$$

Where $V_{\text {grid }}$ is volume of grid cells, $N_{p}$ is number of particles per grid.

The influence of the sublattice scale is expressed by GSG stress as equation (4):

$$
\tau_{\mathrm{i} j}^{\mathrm{r}}=\overline{u_{i} u_{j}}-\bar{u}_{i} \bar{u}_{j}
$$

And the equation of particle motion can be written as:

$$
\begin{gathered}
\frac{d x_{p i}(t)}{d t}=u_{p i}(t) \\
\frac{d u_{p i}(t)}{d t}=\frac{u_{i}\left[x_{p i}(t), t\right]-u_{p i}(t)}{\tau_{p}} f\left(\operatorname{Re}_{p}\right)+\frac{F_{i}}{\mathrm{~m}_{\mathrm{p}}}
\end{gathered}
$$

Where $u_{p i}$ is the particle velocity in the $i$ direction, $u_{i}\left[x_{p i}(t), t\right]$ is the particle velocity at the particle location, $F_{i}$ is the forces component in $i$ direction on particles (such as gravity, electric field force, etc), $m_{p}$ is particle mass, $R e_{p}$ is the particle Reynolds number, the influence of nonlinear drag force is obtained by difference of $f\left(R e_{p}\right)$. $\tau_{p}$ is the relaxation time of particle movement calculated with equation (7):

$$
\tau_{p}=\frac{\mathrm{C}_{\mathrm{c}} \rho_{p} d_{p}^{2}}{18 \rho_{f} v}
$$

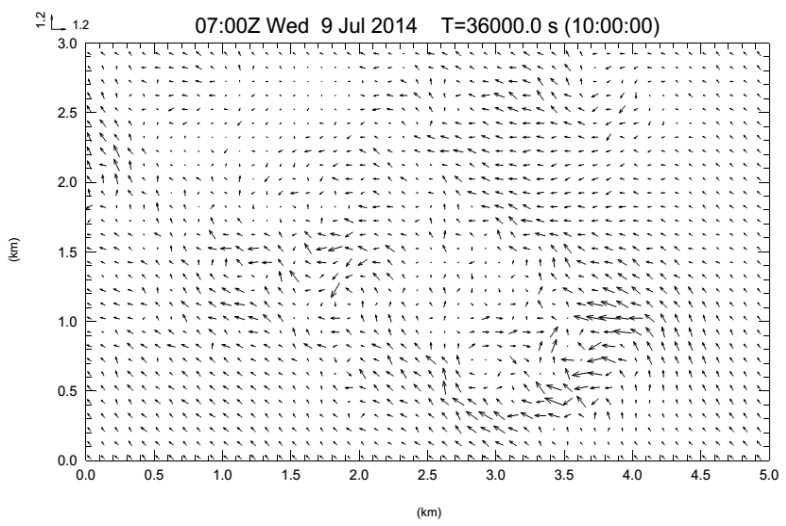

Where $\rho_{p}$ is particle density, $d_{p}$ is particle diameter, $C_{c}$ is Cunningham correction factor.

\subsection{Initial experimental conditions}

The annual average temperature is $-3.4^{\circ} \mathrm{C}$, the average relative humidity is $57 \%$, and the wind speed is about 0 $12 \mathrm{~m} / \mathrm{s}$. The construction time is set at 7:00-20:00 every day. According to the above wind tunnel test results, the dust concentration at the lower boundary of the construction area is set as $100 \mathrm{mg} / \mathrm{m}^{3}$.

Due to differences in the soil characteristics and the particle size of the actual construction site of the highway. So the diffusion of four kinds of dust with different particle sizes, $10 \mu \mathrm{m}, 50 \mu \mathrm{m}$, and $100 \mu \mathrm{m}$, is analyzed in the research. In view of the construction located in the southeast corner of the study area, the dust diffusion under east wind and southeast wind (as shown by the arrow in Figure 4) are considered in the simulation.

\section{Analysis of simulating results}

\subsection{Wind field analysis}

The simulation of the wind field is the basis of the accurate simulation of dust diffusion. Based on the large eddy simulation method, combined with high-precision grid, the wind field and turbulence structure under complex terrain conditions can be simulated accurately. Figure 4 shows the Wind speed vector diagram of the wind field of $10 \mathrm{~m}$ and $1 \mathrm{~m}$ above the ground with southeast wind.

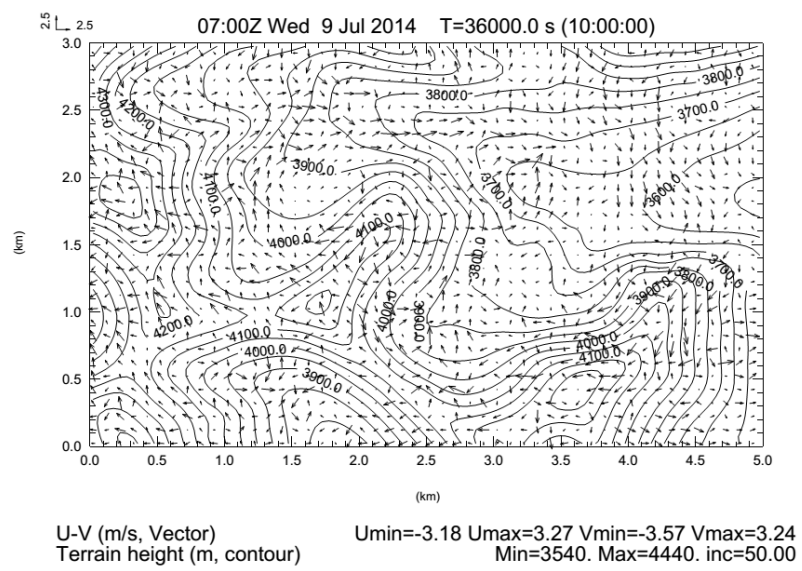

Figure 4. Vector diagram of wind field (the main wind direction is southeast) with a distance of $10 \mathrm{~m}$ and $1 \mathrm{~m}$ above the ground after 10 hours. 
It can be seen from Figure 4, that a large number of flow and turbulence vortices formed around the terrain, and the change of wind speed and direction near the ground is very severe. There is a noticeable acceleration effect on the windward slope of the territory. Under the action of the complex wind field, dust particles move with complex flow field, and its influence range and intensity are directly related to the local wind field. Due to the complexity of the terrain and the lack of wind speed information, the average wind speed applied at the entrance is $6-8 \mathrm{~m} / \mathrm{s}$. Under the effect of terrain acceleration and flow around the terrain, the average wind speed along the main wind direction near the ground is about $12 \mathrm{~m} / \mathrm{s}$, and the local maximum wind speed can reach $25 \mathrm{~m} / \mathrm{s}$.
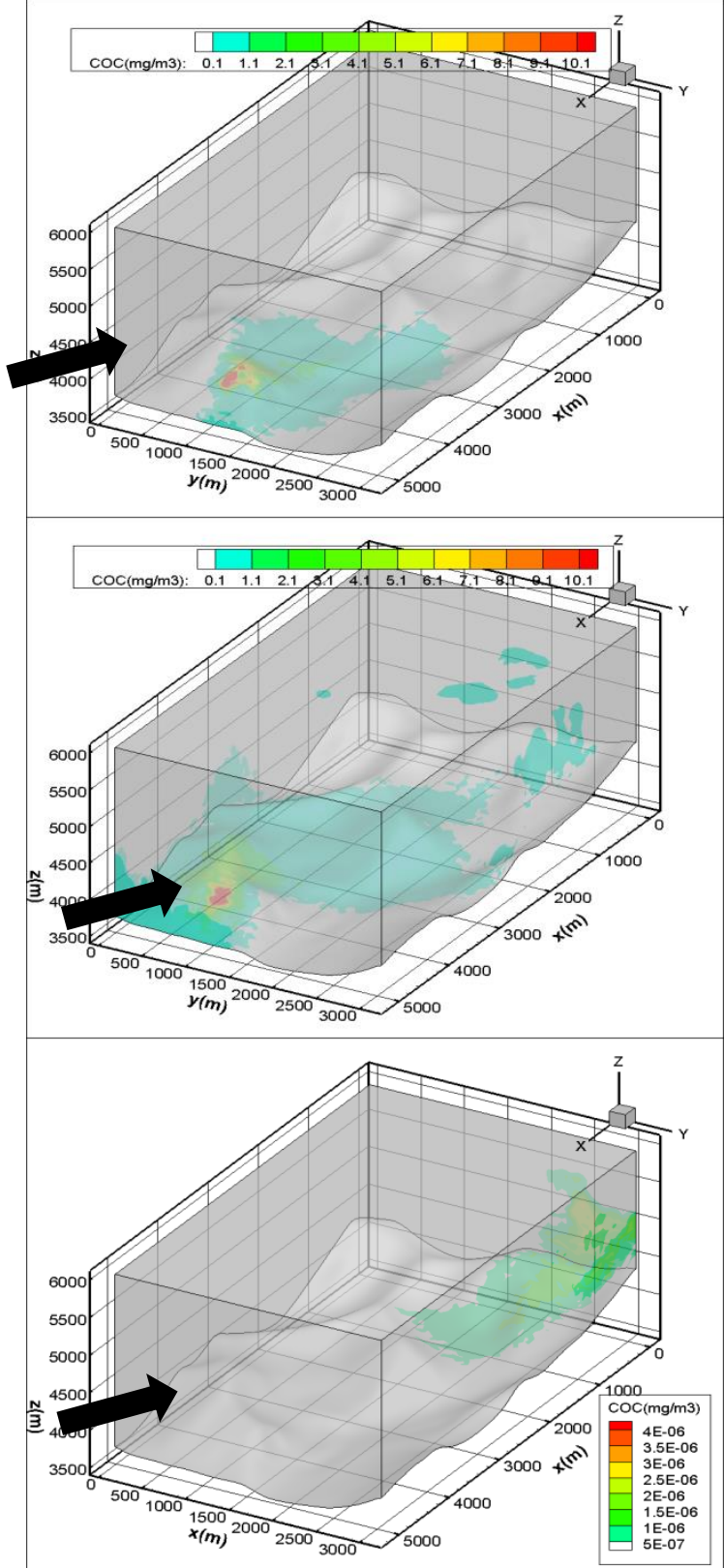

\subsection{Dust diffusion results}

\subsubsection{The diffusion results of $10 \mu \mathrm{m}$ particle size under southeast monsoon.}

Figure 5 shows the simulation results of horizontal diffusion for dust size of $10 \mu \mathrm{m}$ under southeast monsoon. In the figure, the dust concentration distribution nephogram of $0.5 \mathrm{~h}, 3 \mathrm{~h}, 10 \mathrm{~h}, 13 \mathrm{~h}, 18 \mathrm{~h}$ and $24 \mathrm{~h}$ after the dust starts to release is shown in turn. In the light of the construction time, the dust will stop releasing from $13 \mathrm{~h}$.
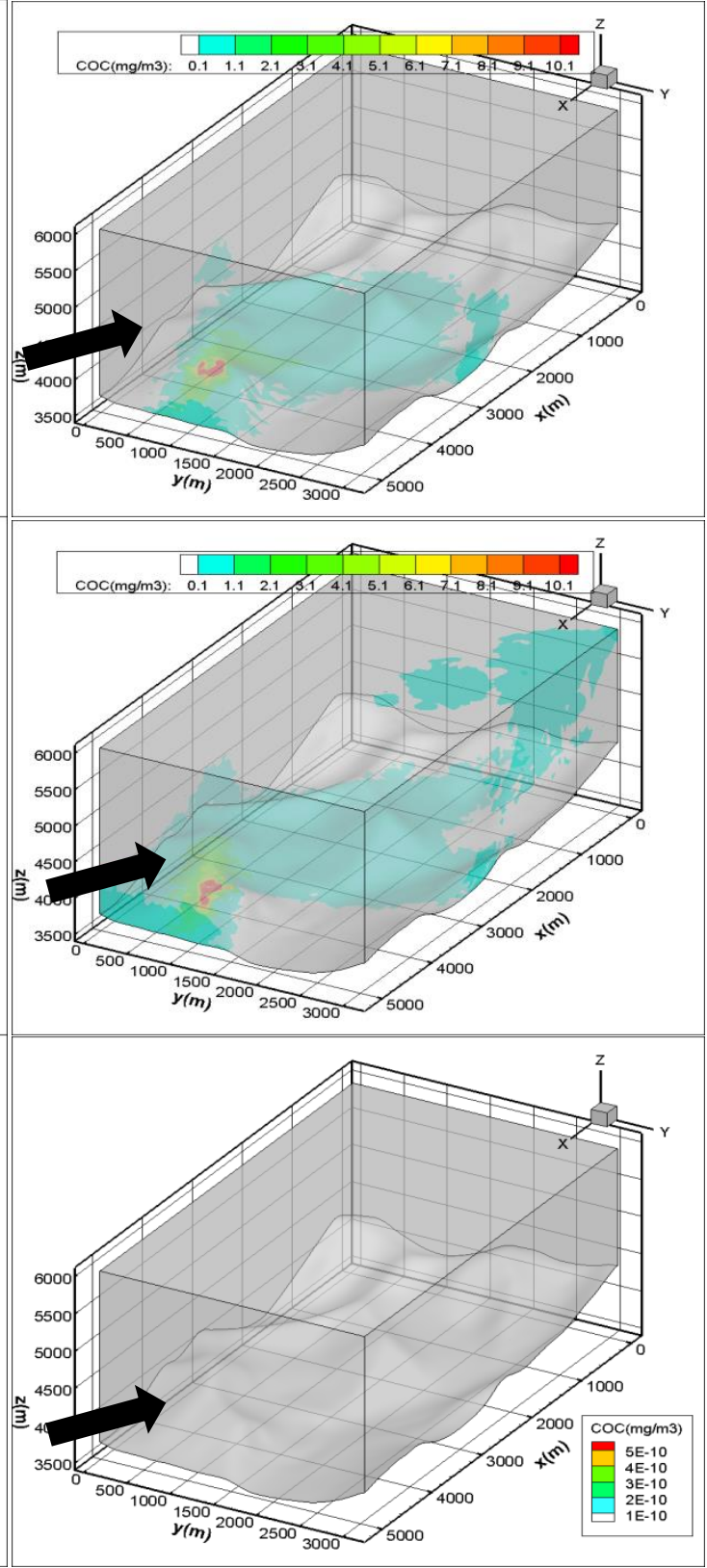

Figure 5. Cloud chart of dust concentration distribution after $0.5 \mathrm{~h}, 3 \mathrm{~h}, 10 \mathrm{~h}, 13 \mathrm{~h}, 18 \mathrm{~h}$ and $24 \mathrm{~h}$ of dust release.

From Figure 5, we can see that the dust rapidly expands outward along the predominant wind direction after the dust released. The small particle size dust with excellent floating characteristics in the wind, therefore it 
can spread very far and high. After the dust stops releasing, the dust concentration in the area decreases rapidly, and gradually moves out of the area along the main wind direction. By the time of $18 \mathrm{~h}$, the dust concentration in the region has dropped to $10-6 \mathrm{~g} / \mathrm{m}^{3}$, and it is almost zero by $24 \mathrm{~h}$. Based on the influence range of dust, $10 \mu \mathrm{m}$ dust penetrates the whole area. For the area with large dust concentration $\left(>4 \mathrm{mg} / \mathrm{m}^{3}\right.$ (GBZ2.12007)), it is mainly distributed within $1000 \mathrm{~m}$ from the release source, and the specific extension direction is
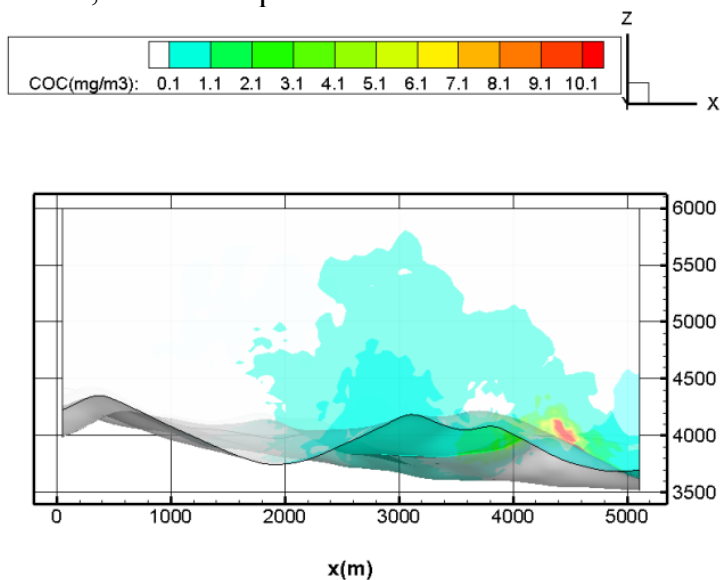

directly related to the local topography and wind direction.

Figure 6 shows the cloud chart of dust concentration height distribution in the southeast scenery with the dust particle size of $10 \mu \mathrm{m}$ and the main wind direction after the dust starts to release for 3 and 5 hours. It can be seen that $10 \mu \mathrm{m}$ dust can reach a very high altitude, but the dust concentration greater than $4 \mathrm{mg} / \mathrm{m}^{3}$ is generally lower than $300 \mathrm{~m}$ in height.
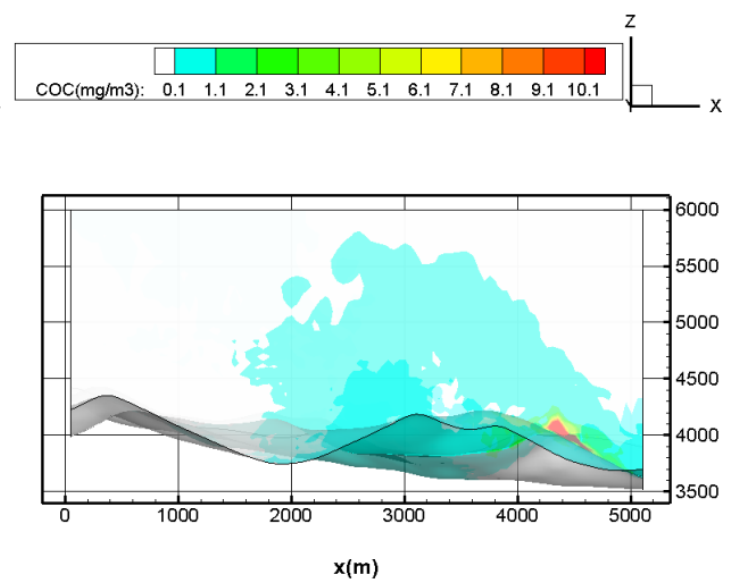

Figure 6. Cloud chart of dust concentration height distribution after 3 and 5 hours of dust release.

\subsubsection{The diffusion results of $50 \mu \mathrm{m}$ particle size under southeast monsoon.}

Figure 7 shows the cloud chart of dust concentration distribution at $0.5 \mathrm{~h}, 1 \mathrm{H}, 3 \mathrm{H}$ and $5 \mathrm{~h}$ after releasing the dust which size is $50 \mu \mathrm{m}$ under east wind. It can be seen from the figure that the dust gradually expands outwards with the increase of release time. The main wind
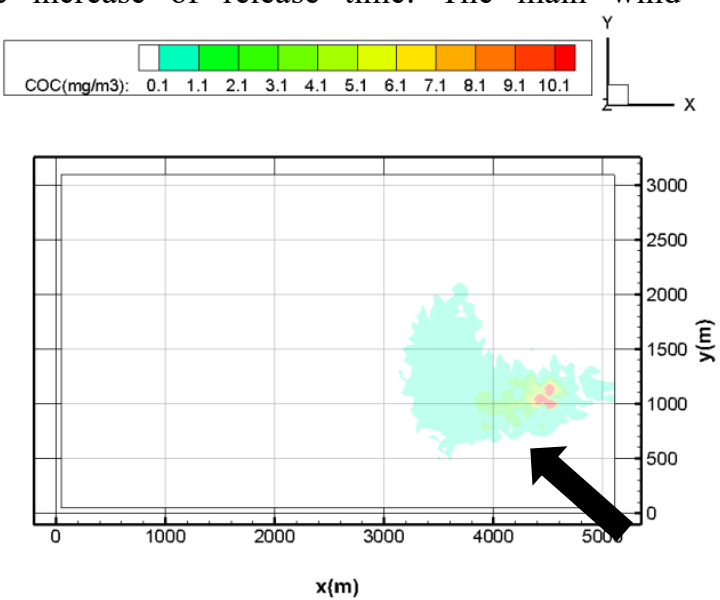

direction is the spread direction most rapidly, and then the dust range tends to be stable after $3 \mathrm{~h}$.

Under the local topography and given meteorological conditions, the impact distance of dust with the particle size of $50 \mu \mathrm{m}$ to the west is about $2000 \mathrm{~m}$, the impact distance to east, north and south are all more than 1000 $\mathrm{m}$.

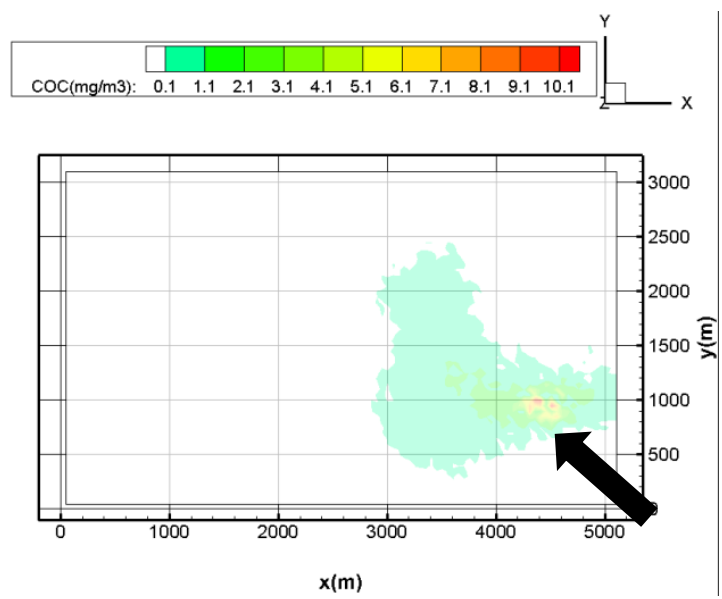



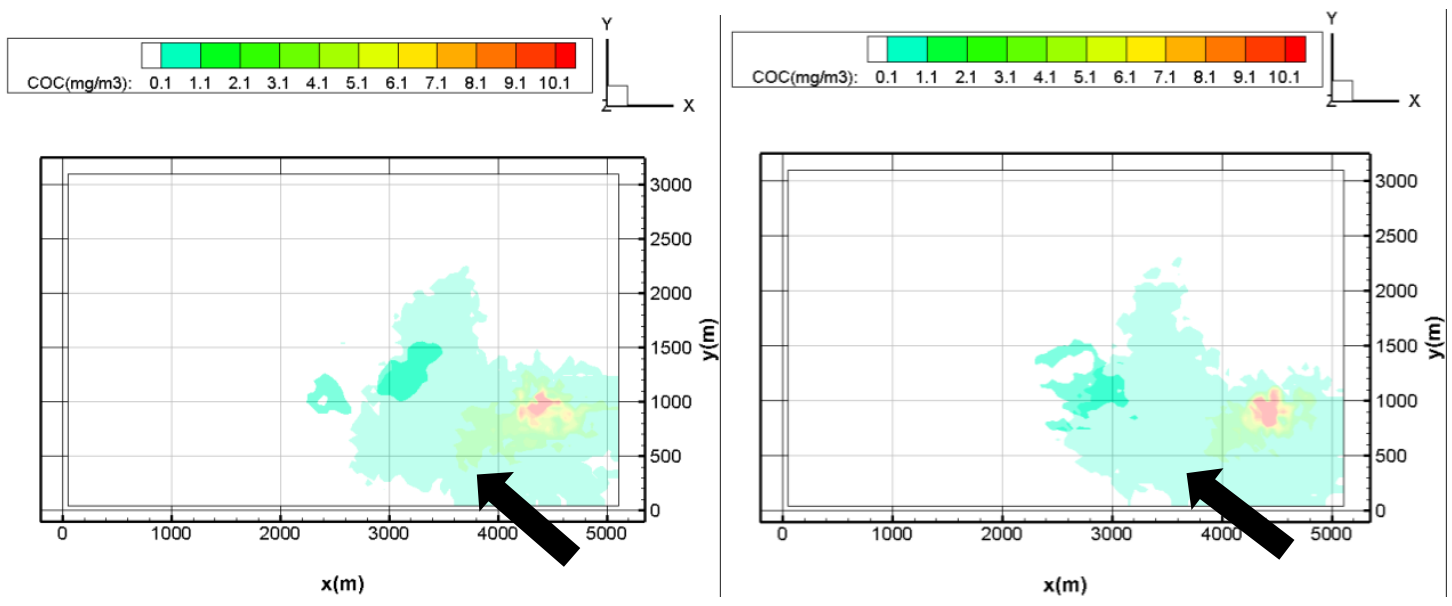

Figure 7. Cloud chart of dust concentration distribution after $0.5 \mathrm{~h}, 1 \mathrm{H}, 3 \mathrm{H}$ and $5 \mathrm{~h}$ of dust release.

Figure 8 is the cloud chart of $50 \mu \mathrm{m}$ dust concentration distribution with height under the southeast wind. It can be seen from figure 10 that the influence range of dust in the height direction exceeds $3000 \mathrm{~m}$. Under the condition of southeast wind and $50 \mu \mathrm{m}$ dust particle size, the influence range of vertical direction of dust is significantly increased in complex terrain. And
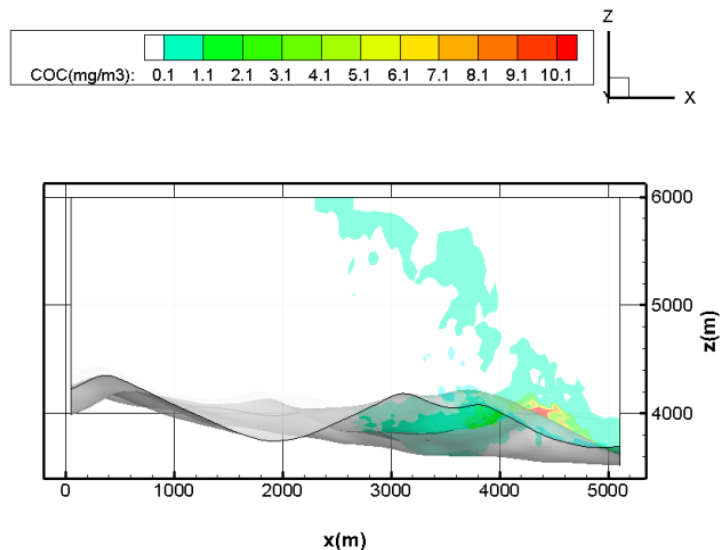

the area with dust concentration greater than $4 \mathrm{mg} / \mathrm{m}^{3}$ is mainly distributed within $1000 \mathrm{~m}$ of the dust release source in the horizontal direction, while is less than $300 \mathrm{~m}$ extending in the height direction along the southwest direction.

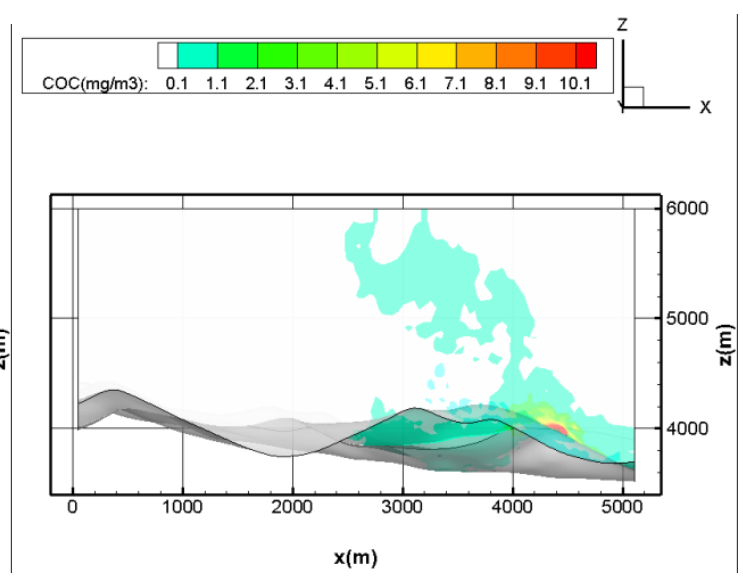

Figure 8. Cloud chart of dust concentration height distribution $1 \mathrm{~h}$ and $5 \mathrm{~h}$ after releasing the dust.

\subsubsection{The diffusion results of $50 \mu \mathrm{m}$ particle size under east wind.}

From Figure 9 and Figure 10, we can see the simulation results of $50 \mu \mathrm{m}$ horizontal dust diffusion and vertical diffusion under the main wind direction of the east wind. It can be seen from the figures that after releasing the dust, dust concentration rapidly expands outward with the time, and soon tends to be stable. The reason of which is mainly caused by the terrain of the simulation area, for the dust needs to cross a higher terrain along the main wind direction and forms an active vortex and return area after passing through the terrain. Most of the dust is blocked in front of the terrain due to large particle size and poor follow-up. Some of the dust moving over the terrain is challenging to spread forward for the turbulence wind field. Meanwhile, only a few of them can continue to spread along the main wind direction.

When stopping releasing dust, the dust concentration decreases rapidly, and dust diffuses along the main wind direction. The dust concentration has dropped to 10-7 $\mathrm{g} / \mathrm{m}^{3}$ by 18 hours, and to appoxmately zero by 24 hours. Through comparing with the results of $10 \mu \mathrm{m}$ dust, the settling rate of $50 \mu \mathrm{m}$ dust is higher than that of $10 \mu \mathrm{m}$ dust. From the influence scope of dust, the dust diffusion to the west is about $2000 \mathrm{~m}$, and there is no diffusion to the north. For the large dust concentration greater than 4 $\mathrm{mg} / \mathrm{m}^{3}$, it is mainly distributed within $500 \mathrm{~m}$ from the release source and directly related to the local terrain and wind direction. Under the condition of above dust diffusion, the height direction is not more than $300 \mathrm{~m}$ and the propagation direction is southwest. 

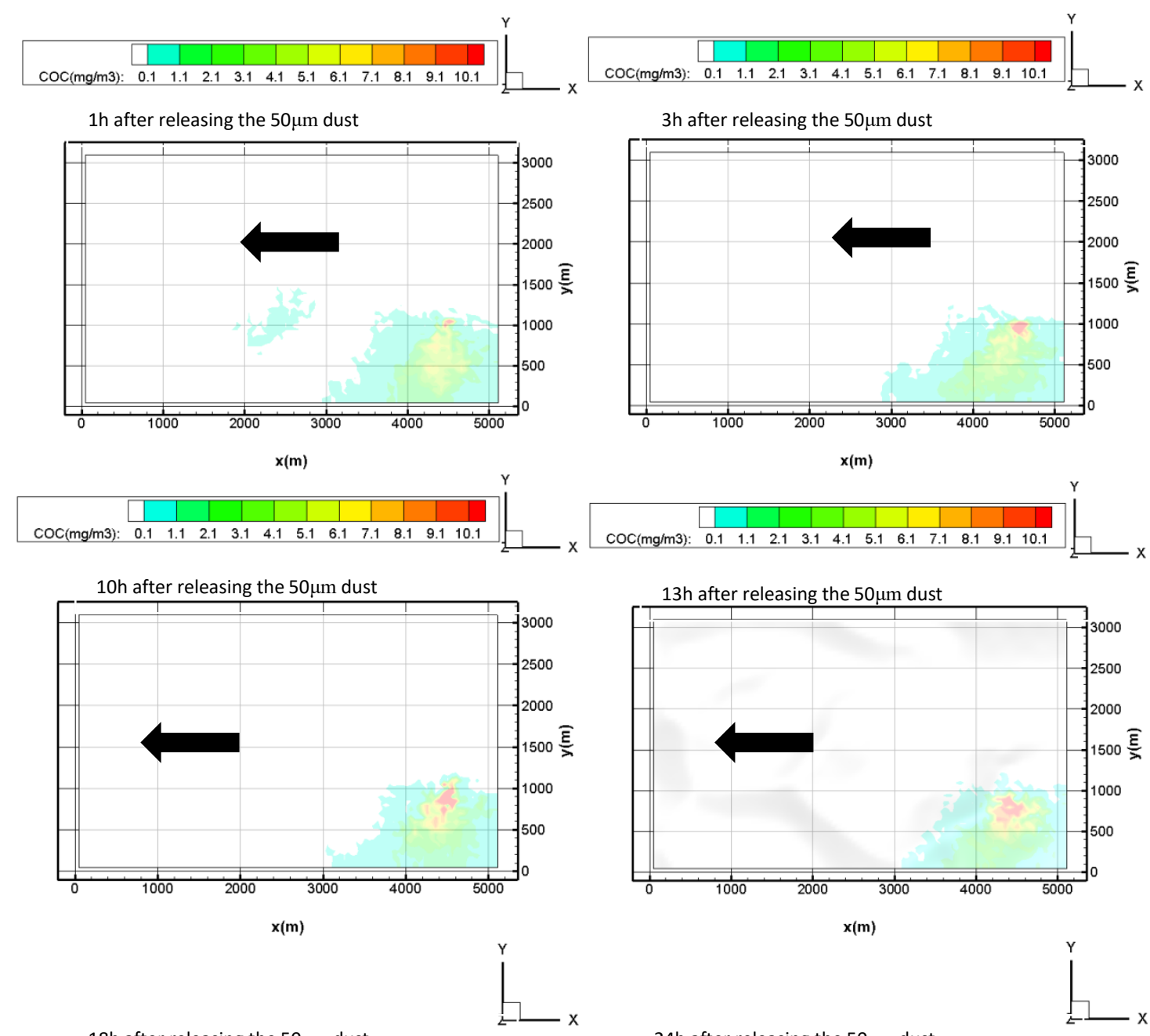

$18 \mathrm{~h}$ after releasing the $50 \mu \mathrm{m}$ dust

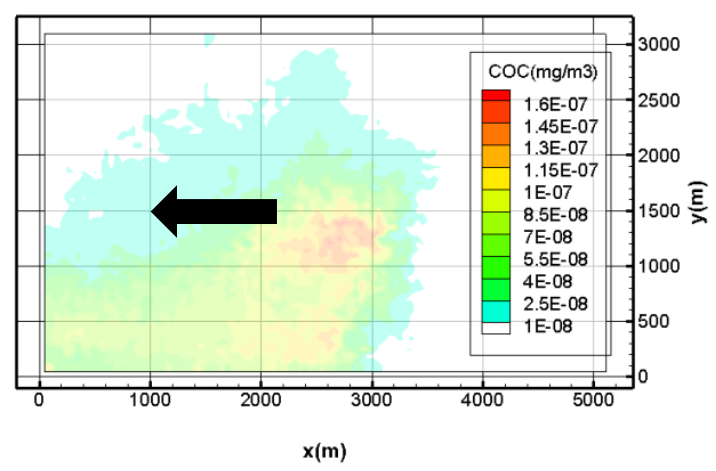

$24 \mathrm{~h}$ after releasing the $50 \mu \mathrm{m}$ dust
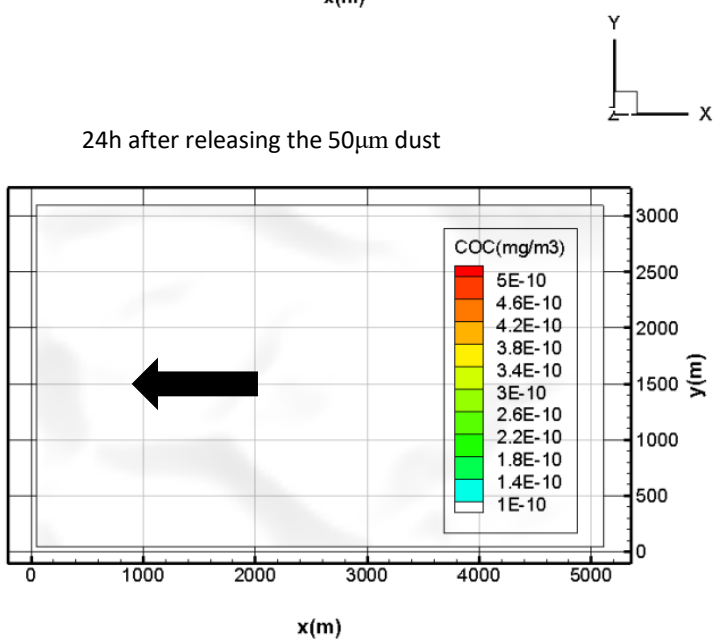

Figure 9. Cloud diagrams of dust concentration distribution after the dust started to release $1 \mathrm{~h}, 3 \mathrm{~h}, 10 \mathrm{~h}, 13 \mathrm{~h}, 18 \mathrm{~h}$ and $24 \mathrm{~h}$ 

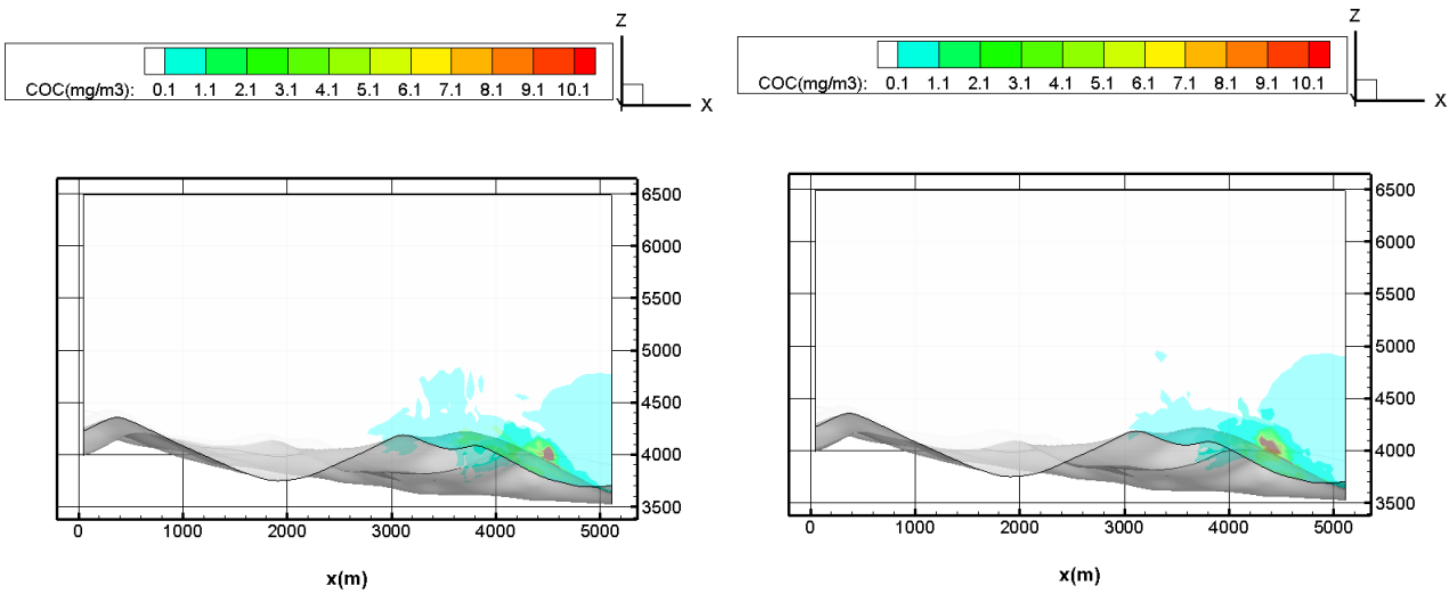

Figure 10. Highly distributed cloud maps of dust concentration after 1 and 5 hours of dust release

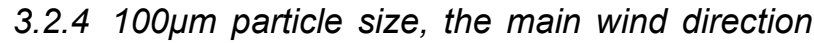 is east wind.}

Figure 11 is a cloud diagram of the dust concentration distribution after the dust started to release for $0.5 \mathrm{~h}, 1 \mathrm{~h}$, $3 \mathrm{~h}$, and $5 \mathrm{~h}$ in the scenario with a particle diameter of $100 \mu \mathrm{m}$ and the main wind direction being the east wind; Figure 12 shows the simulation results of vertical dust diffusion in this scenario.It can be seen from the figure that due to the large particle size of the dust, the extended range of the dust is small, and the range of the dust does not increase basically after 3 hours, indicating that the range of the dust with a particle size of $100 \mu \mathrm{m}$ tends to be stable.
Specifically, given the terrain of a simulated area and given weather conditions, the impact distance of the dust with a particle size of $100 \mu \mathrm{m}$ to the west is about $1000 \mathrm{~m}$, The eastward impact distance is about $500 \mathrm{~m}$, and the north-south impact range is about $1000 \mathrm{~m}$ and $500 \mathrm{~m}$ respectively, The influence range in height direction is generally less than $500 \mathrm{~m}$. Therefore, in the case of the east wind, attention should be paid to the spread of dust to the west and south. Areas with high dust concentration $\left(>4 \mathrm{mg} / \mathrm{m}^{3}\right)$ are distributed within $500 \mathrm{~m}$ from the release source, and the specific extension direction is directly related to the local terrain and wind direction. The propagation direction in this case is the southwest direction and the height direction does not exceed $300 \mathrm{~m}$.
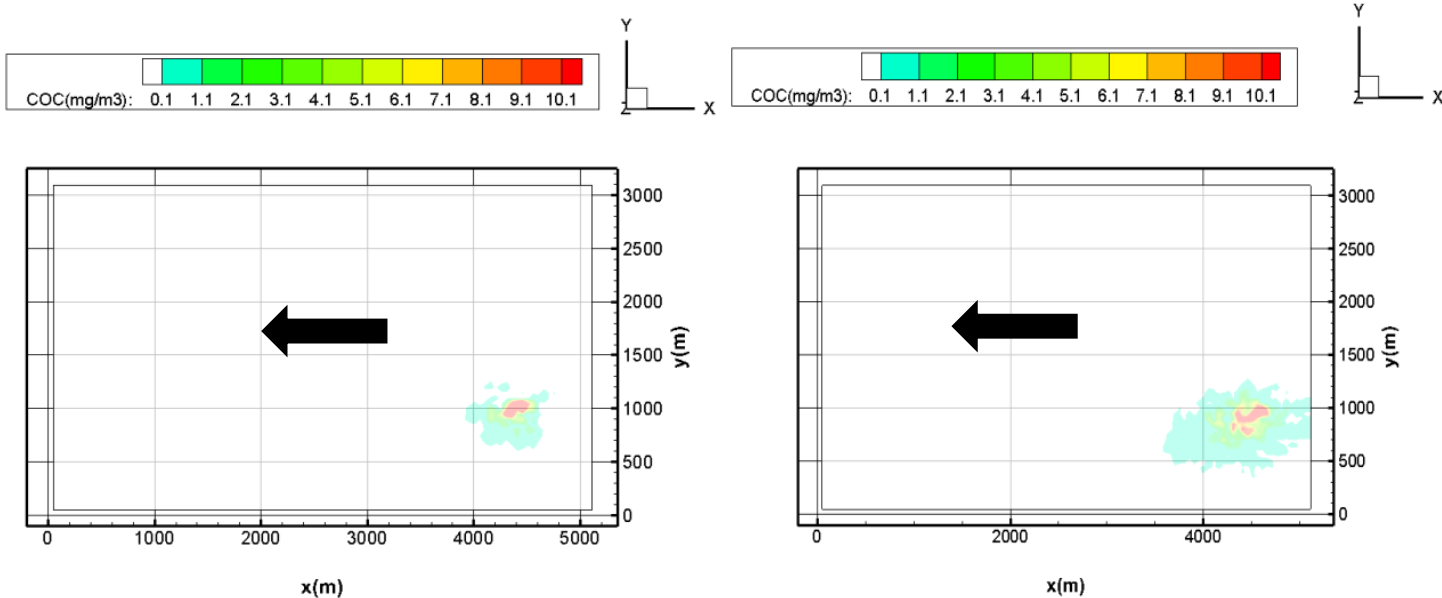

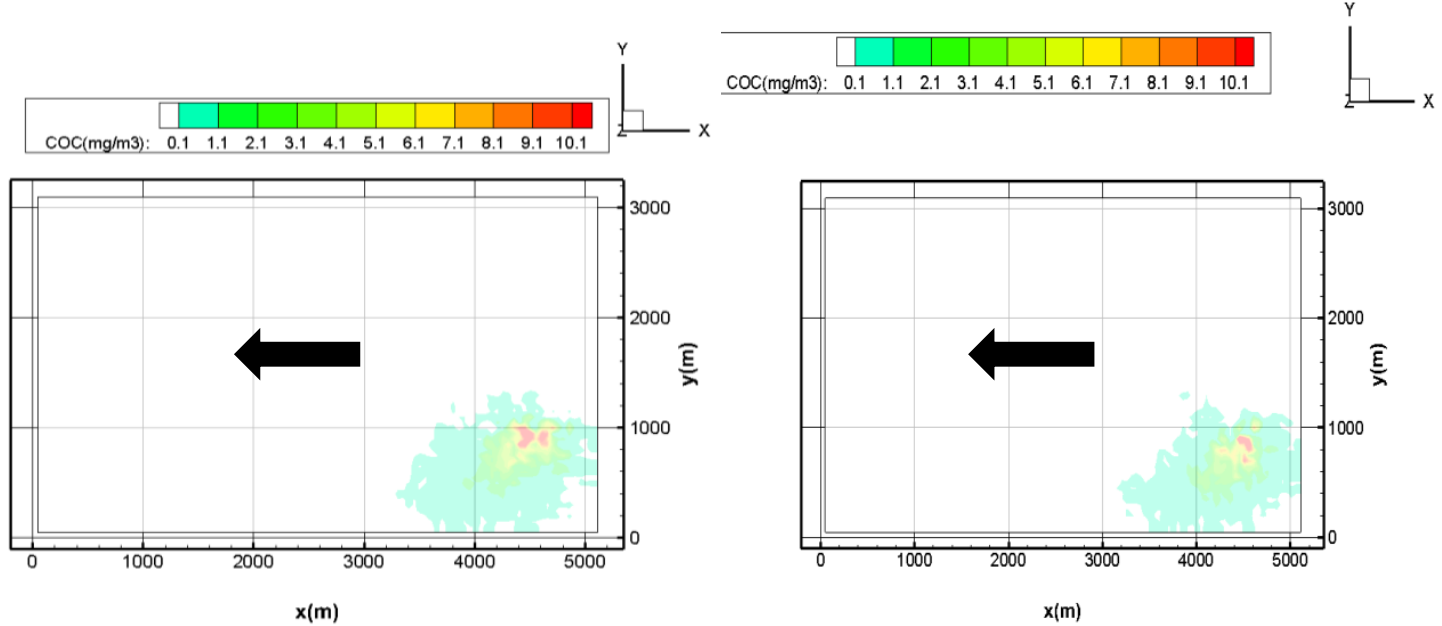

Figure 11. Cloud diagrams of dust concentration distribution after the dust started to release for $0.5 \mathrm{~h}, 1 \mathrm{~h}, 3 \mathrm{~h}$, and $5 \mathrm{~h}$
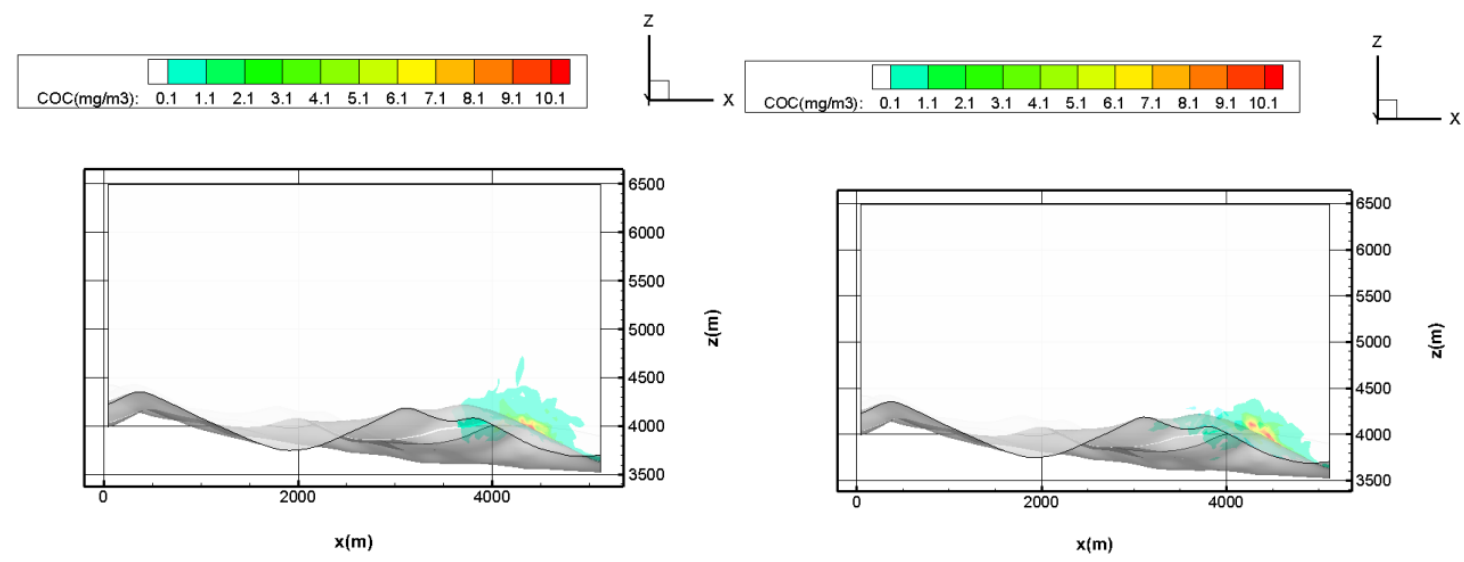

Figure 12. Cloud diagrams of the dust concentration height distribution after the dust started to release for $1 \mathrm{~h}$ and $5 \mathrm{~h}$

\section{Conclusions and recommendations}

\subsection{Conclusions}

Through numerical simulation of the study area under given conditions, this article simulates the diffusion of dust with different particle sizes under different wind directions, analyzes the impact range and intensity of the dust, and draws the main conclusions as follows:

(1) Due to the local complex terrain, dust diffusion has a great relationship with wind direction. According to the location of the construction site, two scenarios in which the main wind direction is east wind and southeast wind are studied. The results show that the range of dust diffusion in the southeast wind is larger than that in the east wind.

(2) The diffusion range of dust is inversely proportional to the particle size of the dust. That is, the larger the particle size, the smaller the diffusion range of the dust; and the sedimentation speed increases with the increase of particle size.

(3) Areas with high dust concentration $\left(>4 \mathrm{mg} / \mathrm{m}^{3}\right)$ are generally distributed within $1000 \mathrm{~m}$ around the construction site. The specific extension direction is directly related to the local terrain and wind direction, and the height direction generally does not exceed $300 \mathrm{~m}$.

\subsection{Countermeasures and suggestions for reducing the impact of Construction Dust on Glacier Environment}

According to the aforementioned wind tunnel experiments and numerical simulation conclusions, in order to reduce the impact of the proposed construction road dust on the glacier environment along the line, the following countermeasures are recommended.

(1) Route selection stage

1) In the absence of natural barriers such as mountains, the horizontal distance between the route line and the edge of the concentrated glaciers should not be less than $1000 \mathrm{~m}$, and the vertical distance should not be less than $300 \mathrm{~m}$; when there is a natural barrier such as a mountain between the route line and the concentrated distribution area of the glacier, the minimum distance between the two can be determined by numerical simulation calculation.

2) When designing the site selection of the borrowing, spoil ground and temporary engineering facilities, the space distance from the edge of the glacial concentrated 
distribution area requires the same route line layout requirements.

(2) Highway construction stage

1) Dust screens should be installed on the sides or around the highway construction site that is closer to the edge of the glacier concentrated distribution area (when the minimum distance requirements are not met).

2) Minimize the construction time of the adjacent glaciers, and regularly spray water or dusting agents on the construction site and surrounding areas to suppress dust.

3) Bare surface wounds formed during construction shall be covered, hardened or protected by greening measures in a timely manner.

4) Fencing facilities should be set up around the precast yard, mixing station and material storage yard, and dust removal facilities should be provided in the mixing building.

\section{References}

1. Research Institute of Highway Science of the Ministry of Transport. Research Report on Impacts of Highway Construction on Ecologically Sensitive Areas such as Glaciers, Wetlands and Water Sources[R],2015.

2. Yang Xinyuan, Han Tianding. Trends of Temperature and Precipitation in the Source of Urumqi River and Their Impacts on Glaciers. Glacial frozen soil. 1996,18(2):189-193.

3. Gao Wenhua, Li Zhongqin, Zhang Mingjun, etc. Characteristics of total soluble solids and suspended particulates in glacial runoff from the source of Urumqi River and analysis of influencing factors. Environmental Chemistry, 2011,30 (5):920-927.

4. Zhou Zaiming, Jing Zhefan, Zhao Shuhui, etc. Response of Glacier Speed to Climate Change-Take the Glacier No. 1 at the source of the Urumqi River in the Tianshan Mountains as an example. Journal of earth, 2010,31(2): 237-24. 